\title{
SHORT- AND LONG-TERM ACCLIMATION PATTERNS OF THE GIANT KELP MACROCYSTIS PYRIFERA (LAMINARIALES, PHAEOPHYCEAE) ALONG A DEPTH GRADIENT $^{1}$
}

\author{
Kristina Koch ${ }^{2}$
}

Marine Botany and Bremen Marine Ecology - Center for Research and Education (BreMarE), University of Bremen, Leobener Str. NW2, 28359 Bremen, Germany

\section{Martin Thiel}

Facultad de Ciencias del Mar, Universidad Católica del Norte and Centro de Estudios Avanzados en Zonas Áridas (CEAZA), Larrondo 1281, Coquimbo, Chile

Nucleus Ecology and Sustainable Management of Oceanic Island (ESMOI), Coquimbo, Chile

\section{Wilhelm Hagen}

Marine Zoology and Bremen Marine Ecology - Center for Research and Education (BreMarE), University of Bremen, Leobener Str. NW2, Bremen 28359, Germany

\section{Martin Graeve}

Ecological Chemistry, Alfred Wegener Institute Helmholtz Centre for Polar and Marine Research (AWI), Am Handelshafen 12, Bremerhaven 27570, Germany

\section{Iván Gómez}

Instituto de Ciencias Marinas y Limnológicas, Universidad Austral de Chile, Casilla 567, Valdivia, Chile

\section{David Jofre}

Facultad de Ciencias del Mar, Universidad Católica del Norte, Larrondo 1281, Coquimbo, Chile

\section{Laurie C. Hofmann}

Marine Botany and Bremen Marine Ecology - Center for Research and Education (BreMarE), University of Bremen, Leobener Str. NW2, 28359 Bremen, Germany

Max Planck Institute for Marine Microbiology, Celsiusstr. 1, Bremen 28359, Germany

\section{Fadia Tala}

Facultad de Ciencias del Mar, Universidad Católica del Norte and Centro de Investigación y Desarrollo Tecnológico en Algas (CIDTA), Larrondo 1281, Coquimbo, Chile

\section{and Kai Bischof}

Marine Botany and Bremen Marine Ecology - Center for Research and Education (BreMarE), University of Bremen, Leobener Str. NW2, 28359 Bremen, Germany

The giant kelp, Macrocystis pyrifera, is exposed to highly variable irradiance and temperature regimes across its geographic and vertical depth gradients. The objective of this study was to extend our understanding of algal acclimation strategies on different temporal scales to those varying abiotic conditions at various water depths. Different acclimation strategies to various water depths $(0.2$

\footnotetext{
${ }^{1}$ Received 22 July 2015. Accepted 11 January 2016.

${ }^{2}$ Author for correspondence: e-mail kristina.koch@unibremen.de.

Editorial Responsibility: T. Wernberg (Associate Editor)
}

and $4 \mathrm{~m}$ ) between different sampling times (Jan/ Feb and Aug/Sept 2012; long-term acclimation) and more rapid adjustments to different depths $(0.2,2$ and $4 \mathrm{~m}$; short-term acclimation) during $14 \mathrm{~d}$ of transplantation were found. Adjustments of variable Chl $a$ fluorescence, pigment composition ( $\mathrm{Chl} c$, fucoxanthin), and the de-epoxidation state of the xanthophyll cycle pigments were responsible for the development of different physiological states with respect to various solar radiation and temperature climates. Interestingly, the results indicated that phlorotannins are important during long-term 
acclimation while antioxidants have a crucial role during short-term acclimation. Furthermore, the results suggested that modifications in total lipids and fatty acid compositions apparently also might play a role in depth acclimation. In Aug/Sept (austral winter), M. pyrifera responded to the transplantation from $4 \mathrm{~m}$ to $0.2 \mathrm{~m}$ depth with a rise in the degree of saturation and a switch from shorter- to longer-chain fatty acids. These changes seem to be essential for the readjustment of thylakoid membranes and might, thus, facilitate efficient photosynthesis under changing irradiances and temperatures. Further experiments are needed to disentangle the relative contribution of solar radiation, temperature and also other abiotic parameters in the observed physiological changes.

Key index words: acclimation; antioxidants; Chile; fatty acid composition; PAR; phlorotannins; temperature; total lipids

Abbreviations: Aug/Sept, August/September; Di, Incubation depth; DPPH, 2,2-diphenyl-1-picrylhydrazyl; DPS, De-epoxidation state of the xanthophyll cycle pigments; Ds, Sampling depth; dw, Dry weight; $\mathbf{E}_{\mathbf{k}}$, Saturating irradiance; ETR, Electron transport rate; ETR $_{\text {max }}$, Maximum electron transport rate (photosynthetic capacity); FA, Fatty acid; FAME, Fatty acid methyl ester derivate; Fuc, Fucoxanthin; $\mathbf{F}_{\mathrm{v}} / \mathbf{F}_{\mathbf{m}}$, Maximum quantum yield; HSD, Honest significant difference; Jan/Feb, January/February; $\mathbf{K}_{\mathrm{d}}$, Vertical attenuation coefficient of downward irradiance; Max, Maximum; Min, Minimum; n.d., Not detected; n.m., Not measured; NPQ, Nonphotochemical quenching of Chl a fluorescence; PAM, Pulse amplitude modulation; PCO, Principal coordinate analysis; P-E curve, Photosynthesis versus irradiance curve; PERMDISP, permutational analysis of multivariate dispersion; PERMANOVA, Permutational multivariate analysis of variance; ratio sat/unsat FA, Saturated/unsaturated fatty acid ratio; ROS, Reactive oxygen species; SD, Standard deviation; SEM, Standard error of the mean; SIMPER, Similarity percentage analysis; TE, Trolox equivalent; Trolox, 6-hydroxy-2,5,7,8-tetramethylchroman-2-carboxylic acid; Ts, Sampling time; UCN, Universidad Católica del Norte; VAZ, Xanthophyll cycle pigment pool; ww, Wet weight; $\alpha$, Initial linear slope of P-E curve (photosynthetic efficiency); $\beta$-caro, $\beta$-carotene

The giant kelp, Macrocystis pyrifera (L.) C. Agardh, reaches sizes up to $60 \mathrm{~m}$, and hence, a single sporophyte may span the entire water column from the bottom to the sea surface (North 1994). The kelp is attached to the substratum by a hapterous holdfast and its numerous fronds are maintained vertically in the water column by gas-filled pneumatocysts that may reach the sea surface (North 1994), where they form a dense floating canopy (Gerard 1984, Dean 1985). Macrocystis pyrifera is an ecologically impor- tant species throughout its distribution range along the west coast of North America and cold-temperate waters of the southern hemisphere with growing economic importance in South America and southern California, USA (Buschmann et al. 2014a, Westermeier et al. 2014). The species exhibits high primary production rates (Towle and Pearse 1973, North 1994) and provides three-dimensional habitats, food sources and nursery grounds for associated invertebrates and fishes (Graham et al. 2007, Pérez-Matus et al. 2007, Villegas et al. 2008). Additionally, sporophytes may become detached from the substratum and may act as long-distance dispersal vectors during their extensive free-floating periods $(\sim 1,000 \mathrm{~km}$ in $100 \mathrm{~d}$; Macaya et al. 2005, Thiel and Haye 2006, Rothäusler et al. 2012).

Given its ability to grow along extensive latitudinal and vertical depth gradients and to float at the sea surface, the giant kelp must have developed various acclimation mechanisms to cope with the extreme variability in abiotic conditions. For example, surface waters exhibit distinct temperature differences along the wave-exposed Chilean coast, with summer values of $>20^{\circ} \mathrm{C}$ in the North and $<14^{\circ} \mathrm{C}$ in the South (Rothäusler et al. 2009). In the wave-protected channels and fjords in southern Chile, temperature can even range from $8^{\circ} \mathrm{C}$ to $15^{\circ} \mathrm{C}$ (Buschmann et al. 2004). Further, within a kelp forest, pronounced vertical gradients of irradiance, temperature, and nutrients exist (North 1971, Dean 1985). The prevailing sunlight at the surface can be reduced by $63 \%-78 \%$ directly under the canopy (Huovinen and Gómez 2011) and by $99 \%$ at $20 \mathrm{~m}$ depth (Dean 1985).

Several studies, focusing mainly on photosynthesis and pigments of $M$. pyrifera under different temperature and light conditions, revealed that algal acclimation patterns depend on the position of the photosynthetic tissue in the water column. Gerard (1986) found that surface blades of the giant kelp from southern California exhibit no short-term photoinhibition under high light conditions, whereas the photosynthetic rates of deeper blades are strongly depressed during exposure to the same irradiance. Also, photoprotection (e.g., accumulation of xanthophyll cycle pigments and increase in non-photochemical quenching (NPQ) rates of Chl $a$ fluorescence) is favored in surface blades (Colombo-Pallotta et al. 2006, García-Mendoza and Colombo-Pallotta 2007), whereas light-harvesting is enhanced in deeper blades (Wheeler 1980, Smith and Melis 1987).

Adjustments of phlorotannin and antioxidant levels are further known to contribute to the acclimation potential of Phaeophyceae to different abiotic conditions. Phlorotannins are suggested to act as sunscreen substances against potentially harmful solar radiation (high PAR and UV) in brown algae (Schoenwaelder and Clayton 1998, Schoenwaelder 2002, Swanson and Fox 2007, Cruces et al. 2012). 
These authors further detected a correlation between phlorotannins and antioxidants, which function as scavengers of reactive oxygen species (ROS), in M. pyrifera. Since ROS can damage proteins and lipids, thylakoid membrane integrity might not be maintained and stress-induced repair processes of membranes might be slowed down, resulting in severe decreases of photosynthetic capacity (Bischof and Rautenberger 2012). Thus, changes in abiotic conditions may also result in adjustments of the fatty acid (FA) composition (e.g., Becker et al. 2010). Optimum membrane fluidity, which is mainly determined by the FA chain length and degree of FA saturation, is essential for proper cell functioning. It is generally accepted that at low temperatures, membranes exhibit higher amounts of shorter-chain and unsaturated FAs with lower melting points. At high temperatures, in contrast, more longer-chain and saturated FAs with higher melting points are incorporated into membranes (Buchanan et al. 2000). Some previous studies pointed out that changes in environmental parameters can cause alterations of the FA profiles of marine macrophytes (e.g., Pettitt and Harwood 1989, Pettitt et al. 1989, Schmid et al. 2014), with habitat conditions rather than the geographic location determining differences in macroalgal FA compositions (Khotimchenko et al. 2002). There is also evidence for seasonal variability in lipid class composition, which was shown for Ulva lobata (Chlorophyta), Egregia menziesii (Phaeophyceae) and Chondracanthus canaliculatus (Rhodophyta; Nelson et al. 2002).

Based on the above considerations, the objective of this study was to extend our understanding of long- and short-term acclimation strategies of $M$. pyrifera to varying environmental conditions at different water depths. Given the multitude of abiotic factors, shaping the algal environments at various water depths, we concentrated specifically on light and temperature climates in this study. We further focused on kelp sporophytes from intertidal and shallow subtidal habitats because they experience strong fluctuations in abiotic factors. Furthermore, the kelps from those habitats are exposed to wave action and they may consequently experience a high detachment risk. Subsequent floating to the sea surface is followed by abrupt changes in environmental conditions. Since kelp responses to changing abiotic regimes are known to differ between seasons (e.g., Tala et al. 2013), the study was conducted once in January/February and again in August/ September (hereafter Jan/Feb and Aug/Sept) of 2012. We refer to long-term responses as consistent acclimation strategies between different sampling times (Jan/Feb and Aug/Sept), whereas short-term responses were measured after transplantation of kelp fronds to different water depths for $14 \mathrm{~d}$. Kelp responses were determined by measurements of variable Chl $a$ fluorescence of PSII and various biochem- ical parameters (pigment composition, phlorotannin content, antioxidant activity, total lipid content). Another major focus of this study, which had been hardly addressed, was to examine the adjustments in FA composition and their importance in acclimation processes of $M$. pyrifera. We hypothesized that stress tolerance mechanisms, particularly in Jan/Feb samples from surface waters (i.e., during exposure to highest solar radiation and temperature), should operate in a way that phlorotannin and antioxidant levels increase along with membrane FAs with high melting points and that these parameters would further differ with depth.

\section{MATERIALS AND METHODS}

Algal material and sampling site. Approximately $1.5 \mathrm{~m}$ long apical fronds containing stipe, apical meristem and blades were collected at low tide from two $M$. pyrifera kelp forests at the coast of northern-central Chile. Kelp fronds were sampled at $\sim 0.2 \mathrm{~m}$ water depth in Punta de Talca $\left(30^{\circ} 50^{\prime} \mathrm{S}, 71^{\circ} 41^{\prime}\right.$ $\mathrm{W})$ and at $\sim 4 \mathrm{~m}$ water depth in Playa Blanca $\left(28^{\circ} 11^{\prime} \mathrm{S}, 71^{\circ}\right.$ $\left.09^{\prime} \mathrm{W}\right)$. Since along the coast of northern-central Chile almost no Macrocystis populations exist in which sporophytes grow at both water depths, kelp fronds had to be collected at two different locations. Thus, results of this study should be interpreted with the understanding that depth effects are potentially influenced by spatial differences in location of source plants. However, we consider spatial effects to be minimal since: (i) the same haplotype of $M$. pyrifera occurs at both locations, suggesting that there are no genetic differences between the kelp individuals from the two sites (Macaya and Zuccarello 2010) and (ii) although climatic as well as oceanographic conditions can vary locally at the two distinct sites (in the past and/or present), overall, abiotic parameters are comparable within coastal regions of northern-central Chile (Hormazabal and Shaffer 2002, Garreaud et al. 2011, Tapia et al. 2014).

At each location, 20 apical fronds were taken from independent sporophytes in Jan/Feb and Aug/Sept 2012. Apical kelp fronds were kept in darkness and immediately transported in coolers with seawater at ambient water temperature to the marine laboratory at Universidad Católica del Norte (UCN) in Coquimbo, Chile $\left(29^{\circ} 57^{\prime} \mathrm{S}, 71^{\circ} 20^{\prime} \mathrm{W}\right)$, where they were stored overnight in large outdoor flow-through seawater tanks $(\sim 2,000 \mathrm{~L})$.

Measurement of abiotic conditions at various water depths. Since in this study apical kelp fronds were incubated at different water depths in the Bahía La Herradura, Coquimbo, Chile, a bay located in the vicinity of the marine laboratory at the UCN, prevailing irradiance of PAR (400-700 nm) and water temperature were monitored throughout the course of the experiment (Table 1). Underwater PAR was measured around noon (12:00-14:00 $\mathrm{h}$, local time) every 1-3 d with a LI-192 cosine corrected underwater quantum sensor connected to a LI-1400 data logger (LiCor, Lincoln, NE, USA) at the three water depths. These measurements were conducted at three different positions along the line of buoys (for details see below) and respective mean values were calculated. In addition, the vertical attenuation coefficient of downward irradiance $\left(\mathrm{K}_{\mathrm{d}}\right)$ was calculated after Kirk (1994). Water temperature was determined every 3 min with a Hobo ${ }^{\circledR}$ TidbiT v2 water temperature logger (Onset Computer Cooperation, Bourne, MA, USA) at $0.2 \mathrm{~m}$ and $6 \mathrm{~m}$ depth. Due to logistical constraints, temperature measurements at 2 and $4 \mathrm{~m}$ water depth were not possible. PAR and water temperature data 
TABLE 1. Average, minimum, and maximum (a) PAR ( $\mu$ mol photons $\cdot \mathrm{m}^{-2} \cdot \mathrm{s}^{-1}$ ); (b) vertical attenuation coefficients of downward irradiance $\left(\mathrm{K}_{\mathrm{d}}, \mathrm{m}^{-1}\right)$; and $(\mathrm{c})$ seawater temperatures $\left({ }^{\circ} \mathrm{C}\right)$, measured during the entire experimental duration in January/February (Jan/Feb) and August/September (Aug/Sept) 2012 in the Bahía La Herradura, Coquimbo, Chile. $\mathrm{K}_{\mathrm{d}}$ was calculated for the entire experimental depth gradient $(0.2-4 \mathrm{~m})$.

\begin{tabular}{|c|c|c|c|c|c|c|c|c|}
\hline & \multicolumn{4}{|c|}{ Jan/Feb 2012} & \multicolumn{4}{|c|}{ Aug/Sept 2012} \\
\hline & $0.2 \mathrm{~m}$ & $2 \mathrm{~m}$ & $4 \mathrm{~m}$ & $6 \mathrm{~m}$ & $0.2 \mathrm{~m}$ & $2 \mathrm{~m}$ & $4 \mathrm{~m}$ & $6 \mathrm{~m}$ \\
\hline \multicolumn{9}{|l|}{ (a) PAR } \\
\hline Mean \pm SD & $1,777 \pm 351$ & $756 \pm 174$ & $389 \pm 141$ & n.m. & $818 \pm 454$ & $310 \pm 235$ & $173 \pm 144$ & n.m. \\
\hline Min & 1,050 & 400 & 200 & n.m. & 153 & & & n.m. \\
\hline Max & 2,200 & 1,100 & 750 & n.m. & 1,720 & 964 & 671 & n.m. \\
\hline \multicolumn{9}{|l|}{ (b) $\mathrm{K}_{\mathrm{d}}$} \\
\hline Mean \pm SD & & $0.41 \pm 0.07$ & & & & $0.46 \pm 0.12$ & & \\
\hline Min & & 0.26 & & & & 0.24 & & \\
\hline Max & & 0.59 & & & & 0.94 & & \\
\hline \multicolumn{9}{|c|}{ (c) seawater temperatures } \\
\hline Mean $\pm S D$ & $18.0 \pm 0.9$ & n.m. & n.m. & $16.5 \pm 1.0$ & $13.9 \pm 0.4$ & n.m. & n.m. & $13.6 \pm 0.4$ \\
\hline Min & 15.7 & n.m. & n.m. & 13.4 & 13.1 & n.m. & n.m. & 13.0 \\
\hline $\operatorname{Max}$ & 20.3 & n.m. & n.m. & 18.8 & 15.1 & n.m. & n.m. & 14.6 \\
\hline
\end{tabular}

Min, minimum; max, maximum; SD, standard deviation; n.m., not measured.

were expressed as total mean values during the 14-d experiment.

Experimental test of short- and long-term depth acclimation. We conducted a 14-d transplantation experiment in the semienclosed Bahía La Herradura, Coquimbo, Chile to investigate short-term acclimation responses of $M$. pyrifera to varying light and temperature climates at different water depths. The experiment was performed once in Jan/Feb and repeated in Aug/Sept. At the start of the experiment (day 0), five initial apical kelp fronds (hereafter initial fronds) were selected for the determination of the physiological status of $M$. pyrifera in the field, while the remaining 15 apical fronds were prepared for the transplantation experiment. For this, apical kelp fronds were shortened to a length of $\sim 1 \mathrm{~m}$ (including the stipe with the apical meristem and seven subsequent free intact blades; hereafter experimental fronds) and tethered at three different depths $(0.2,2$, and $4 \mathrm{~m})$ along vertical lines. Five vertical lines were used for experimental fronds from $0.2 \mathrm{~m}$ sampling depth (Punta de Talca) and five vertical lines were used for experimental fronds from $4 \mathrm{~m}$ sampling depth (Playa Blanca). Each of these vertical lines was equipped with one experimental frond at $0.2 \mathrm{~m}$, one at $2 \mathrm{~m}$, and one at $4 \mathrm{~m}$ incubation depth. The vertical lines were weighed down by a stone and tied to a line of buoys in the bay with 1-2 m distance from each other. The assignation of experimental fronds to depth treatments and the positioning of the vertical lines along the line of buoys was randomized. Wave action led to losses of experimental fronds, so that in exceptional cases fewer than five fronds per water depth $(0.2,2$, and $4 \mathrm{~m}$ ) were left at the end of the experiment (for details see Tables 2 and 3, Tables S1 and S2 in the Supporting Information; Fig. 1).

Measurement of algal responses to short- and long-term depth exposure. At the start of the transplantation experiment (day 0), all response variables (see below) were measured from five initial fronds to determine long-term acclimation responses of $M$. pyrifera to both sampling times and depths. To test further for the transplantation effects on each physiological variable of experimental fronds, their short-term responses were monitored on day 14 of the experiment. Thereby, due to the limitations of the chosen experimental set-up, algal fronds, sampled at 0.2 or $4 \mathrm{~m}$ water depth and incubated at the same depth during the transplantation experiment, respectively, had to serve as controls. Each sampling day (day 0 and 14) started at 09:00 (local time), when vegetative blades of each initial and experimental fronds were sampled and gently cleaned from epibionts. Since individual blades of apical kelp fronds differ in their age and developmental history, we pooled blades for measurements of the different response variables in order to obtain representative replicate samples from each apical frond. For each apical frond, a total of 16 disks (1.5-cm diameter) were cut from three vegetative blades with a cork borer. After pooling these 16 disks from each replicate frond in each treatment group, four blade disks were selected at random and pooled as one replicate sample for each biochemical analysis. Measurements of Chl $a$ fluorescence were carried out immediately, whereas the samples for the other physiological analyses were shock-frozen in liquid nitrogen and stored at $-80^{\circ} \mathrm{C}$ until further processing.

Chl a fluorescence: In vivo Chl $a$ fluorescence of PSII was measured with a pulse amplitude-modulated fluorometer (Diving-PAM and PAM 2500; Walz, Effeltrich, Germany in $\mathrm{Jan} / \mathrm{Feb}$ and in Aug/Sept, respectively). For logistical reasons, different fluorometers had to be used during Jan/Feb and Aug/Sept. All measurements were conducted from 09:00 to $12: 00 \mathrm{~h}$ (local time) to reduce any variation in the determined parameters due to diurnal periodicity. The maximum quantum yield $\left(\mathrm{F}_{\mathrm{v}} / \mathrm{F}_{\mathrm{m}}\right)$ was measured in dark adapted (5 min) blade disks. Electron transport rates (ETR) were estimated from rapid photosynthesis versus irradiance curves $(\mathrm{P}-$ $\mathrm{E}$ curves). The blade disks were irradiated with a series of stepwise increasing actinic irradiances $(\sim 150-2,150 \mu \mathrm{mol}$ photons $\cdot \mathrm{m}^{-2} \cdot \mathrm{s}^{-1}$ in Jan/Feb and $\sim 10-1,700 \mu \mathrm{mol}$ photons $\cdot \mathrm{m}^{-2} \cdot \mathrm{s}^{-1}$ in Aug/Sept) at 30 -s intervals, provided by the respective actinic light source of the PAM devices (Schreiber et al. 1994). Subsequently, the photosynthetic capacity $\left(\mathrm{ETR}_{\max }\right.$, maximum electron transport rate), the photosynthetic efficiency ( $\alpha$, initial linear slope) and the saturating irradiance $\left(\mathrm{E}_{\mathrm{k}}\right)$ were defined by P-E curve fitting after Jassby and Platt (1976). Since two PAM devices with different actinic light sources were used for Chl $a$ fluorescence measurements during Jan/Feb and Aug/Sept, the means of the initial values (day 0) were normalized to $100 \%$. This allows a better comparability between samples from both sampling times. We are aware that reliability of P-E parameters derived from a DivingPAM is hampered by potential shifts in the emission spectra 
TABLE 2. Characteristics of variable Chl $a$ fluorescence of PSII of initial fronds of Macrocystis pyrifera (Day 0) from two different sampling depths $(0.2$ and $4 \mathrm{~m})$ and experimental fronds of $M$. pyrifera (Day 14), transplanted along the depth gradient (0.2 and $4 \mathrm{~m}$ ) during January/February (Jan/Feb) and August/September (Aug/Sept) 2012.

\begin{tabular}{|c|c|c|c|c|c|c|}
\hline \multirow{2}{*}{$\begin{array}{l}\text { Parameter of Chl } \\
a \text { fluorescence }\end{array}$} & \multirow{2}{*}{$\begin{array}{c}\text { Sampling } \\
\text { depth (m) }\end{array}$} & \multirow{2}{*}{$\begin{array}{l}\text { Incubation } \\
\text { depth }(\mathrm{m})\end{array}$} & \multicolumn{2}{|c|}{ Jan/Feb 2012} & \multicolumn{2}{|c|}{ Aug/Sept 2012} \\
\hline & & & Day 0 & Day 14 (\% of initial) & Day 0 & Day 14 (\% of initial) \\
\hline \multirow[t]{4}{*}{$\mathrm{F}_{\mathrm{v}} / \mathrm{F}_{\mathrm{m}}$} & 0.2 & 0.2 & $0.660 \pm 0.007$ & $90 \pm 4$ & $0.728 \pm 0.009$ & $96 \pm 3$ \\
\hline & 0.2 & 4 & & $115 \pm 2$ & & $99 \pm 2$ \\
\hline & 4 & 0.2 & & $100^{\mathrm{a}}$ & & $96 \pm 1$ \\
\hline & 4 & 4 & $0.620 \pm 0.020$ & $107 \pm 3$ & $0.681 \pm 0.004$ & $106 \pm 3^{\mathrm{b}}$ \\
\hline \multirow[t]{4}{*}{$\mathrm{ETR}_{\max }$} & 0.2 & 0.2 & $61.88 \pm 3.63$ & $187 \pm 12$ & $31.75 \pm 3.64$ & $98 \pm 6$ \\
\hline & 0.2 & 4 & & $219 \pm 10$ & & $108 \pm 13$ \\
\hline & 4 & 0.2 & & $555^{\mathrm{a}}$ & & $161 \pm 18$ \\
\hline & 4 & 4 & $28.55 \pm 2.00$ & $436 \pm 16$ & $19.23 \pm 1.64$ & $124 \pm 22^{\mathrm{b}}$ \\
\hline \multirow[t]{4}{*}{$\mathrm{E}_{\mathrm{k}}$} & 0.2 & 0.2 & $286.98 \pm 19.06$ & $251 \pm 17$ & $121.60 \pm 18.12$ & $94 \pm 7$ \\
\hline & 0.2 & 4 & & $154 \pm 9$ & & $107 \pm 16$ \\
\hline & 4 & 0.2 & & $763^{\mathrm{a}}$ & & $137 \pm 7$ \\
\hline & 4 & 4 & $120.30 \pm 17.49$ & $468 \pm 68$ & $87.69 \pm 10.32$ & $96 \pm 18^{\mathrm{b}}$ \\
\hline \multirow[t]{4}{*}{$\alpha$} & 0.2 & 0.2 & $0.217 \pm 0.009$ & $76 \pm 9$ & $0.266 \pm 0.009$ & $103 \pm 3$ \\
\hline & 0.2 & 4 & & $143 \pm 5$ & & $96 \pm 18$ \\
\hline & 4 & 0.2 & & $81^{\mathrm{a}}$ & & $100 \pm 9$ \\
\hline & 4 & 4 & $0.248 \pm 0.024$ & $94 \pm 9$ & $0.223 \pm 0.013$ & $114 \pm 8^{\mathrm{b}}$ \\
\hline
\end{tabular}

Additionally, experimental fronds were also transplanted to $2 \mathrm{~m}$ water depth. Those data are given in Table S2 in the Supporting Information. Different PAM devices were used for the measurements in Jan/Feb and Aug/Sept. To get an impression of the status of variable Chl $a$ fluorescence in the field, data for day 0 are given as absolute values $\left(\mathrm{F}_{\mathrm{\gamma}} / \mathrm{F}_{\mathrm{m}}\right.$ in relative units, $\mathrm{ETR}_{\mathrm{max}}$ in $\mu \mathrm{mol}$ electrons $\cdot \mathrm{m}^{-2} \cdot \mathrm{s}^{-1}, \mathrm{E}_{\mathrm{k}}$ in $\mu \mathrm{mol}$ photons $\cdot \mathrm{m}^{-2} \cdot \mathrm{s}^{-1}$ and $\alpha$ in $\mu \mathrm{mol}$ electrons $\cdot \mathrm{m}^{-2} \cdot \mathrm{s}^{-1}\left(\mu \mathrm{mol} \mathrm{photons}^{\cdot} \mathrm{m}^{-2} \cdot \mathrm{s}^{-1}\right.$ ) ${ }^{-1}$ ). For a better comparability between both sampling times, day 14 values are expressed as $\%$ of initial. Table shows means \pm SEM ( $n=5$ for day 0 and 14 , with exceptions of ${ }^{\mathrm{a}} n=2$ and $\left.{ }^{\mathrm{b}} n=4\right)$.

$\mathrm{SEM}$, standard error of the mean; $\mathrm{F}_{\mathrm{v}} / \mathrm{F}_{\mathrm{m}}$, maximum quantum yield; $\mathrm{ETR}_{\max }$, maximum electron transport rate; $\mathrm{E}_{\mathrm{k}}$, saturating irradiance; $\alpha$, initial linear slope of photosynthesis versus irradiance curve.

TABLE 3. Pigment concentrations $\left(\mu \mathrm{g} \cdot \mathrm{mg}^{-1} \mathrm{dw}\right.$ ) and DPS of initial fronds of Macrocystis pyrifera (Day 0) from two different sampling depths $(0.2$ and $4 \mathrm{~m}$ ) and experimental fronds of $M$. pyrifera (Day 14), transplanted along the depth gradient $(0.2$ and $4 \mathrm{~m})$ during January/February (Jan/Feb) and August/September (Aug/Sept) 2012.

\begin{tabular}{|c|c|c|c|c|c|c|}
\hline \multirow[b]{2}{*}{ Pigment } & \multirow{2}{*}{$\begin{array}{l}\text { Sampling } \\
\text { depth (m) }\end{array}$} & \multirow{2}{*}{$\begin{array}{l}\text { Incubation } \\
\text { depth }(m)\end{array}$} & \multicolumn{2}{|c|}{ Jan/Feb 2012} & \multicolumn{2}{|c|}{ Aug/Sept 2012} \\
\hline & & & Day 0 & Day 14 & Day 0 & Day 14 \\
\hline \multirow[t]{4}{*}{ Chl $a$} & 0.2 & 0.2 & $1.88 \pm 0.25$ & $0.82 \pm 0.15$ & $2.24 \pm 0.36$ & $1.35 \pm 0.22$ \\
\hline & 0.2 & 4 & & $1.96 \pm 0.13$ & & $2.32 \pm 0.18$ \\
\hline & 4 & 0.2 & & $1.05^{\mathrm{a}}$ & & $1.29 \pm 0.06$ \\
\hline & 4 & 4 & $2.39 \pm 0.29$ & $2.07 \pm 0.21$ & $2.27 \pm 0.22$ & $2.06 \pm 0.42^{\mathrm{b}}$ \\
\hline \multirow[t]{4}{*}{ Chl $c$} & 0.2 & 0.2 & $0.15 \pm 0.02$ & $0.05 \pm 0.02$ & $0.20 \pm 0.04$ & $0.11 \pm 0.02$ \\
\hline & 0.2 & 4 & & $0.16 \pm 0.01$ & & $0.26 \pm 0.03$ \\
\hline & 4 & 0.2 & & $0.11^{\mathrm{a}}$ & & $0.11 \pm 0.02$ \\
\hline & 4 & 4 & $0.30 \pm 0.03$ & $0.21 \pm 0.02$ & $0.24 \pm 0.03$ & $0.25 \pm 0.06^{\mathrm{b}}$ \\
\hline \multirow[t]{4}{*}{ Fuc } & 0.2 & 0.2 & $0.62 \pm 0.09$ & $0.29 \pm 0.05$ & $0.79 \pm 0.15$ & $0.46 \pm 0.08$ \\
\hline & 0.2 & 4 & & $0.68 \pm 0.04$ & & $0.93 \pm 0.09$ \\
\hline & 4 & 0.2 & & $0.42^{\mathrm{a}}$ & & $0.40 \pm 0.06$ \\
\hline & 4 & 4 & $1.11 \pm 0.08$ & $0.80 \pm 0.09$ & $1.00 \pm 0.12$ & $0.87 \pm 0.17^{\mathrm{b}}$ \\
\hline \multirow[t]{4}{*}{$\beta$-caro } & 0.2 & 0.2 & $0.08 \pm 0.01$ & $0.06 \pm 0.01$ & $0.12 \pm 0.01$ & $0.10 \pm 0.02$ \\
\hline & 0.2 & 4 & & $0.10 \pm 0.01$ & & $0.11 \pm 0$ \\
\hline & 4 & 0.2 & & $0.07^{\mathrm{a}}$ & & $0.06 \pm 0.01$ \\
\hline & 4 & 4 & $0.07 \pm 0.01$ & $0.08 \pm 0.01$ & $0.10 \pm 0$ & $0.09 \pm 0.01^{\mathrm{b}}$ \\
\hline \multirow[t]{4}{*}{ VAZ } & 0.2 & 0.2 & $0.18 \pm 0.02$ & $0.11 \pm 0.02$ & $0.21 \pm 0.03$ & $0.16 \pm 0.02$ \\
\hline & 0.2 & 4 & & $0.17 \pm 0.01$ & & $0.20 \pm 0.02$ \\
\hline & 4 & 0.2 & & $0.11^{\mathrm{a}}$ & & $0.10 \pm 0$ \\
\hline & 4 & 4 & $0.15 \pm 0.03$ & $0.13 \pm 0.01$ & $0.21 \pm 0.01$ & $0.17 \pm 0.04^{\mathrm{b}}$ \\
\hline \multirow[t]{4}{*}{ DPS } & 0.2 & 0.2 & $0.054 \pm 0.018$ & $0.141 \pm 0.021$ & $0.074 \pm 0.019$ & $0.115 \pm 0.024$ \\
\hline & 0.2 & 4 & & $0.039 \pm 0.008$ & & $0.037 \pm 0.014$ \\
\hline & 4 & 0.2 & & $0.180^{\mathrm{a}}$ & & $0.073 \pm 0.023$ \\
\hline & 4 & 4 & $0.085 \pm 0.012$ & $0.071 \pm 0.019$ & $0.017 \pm 0.001$ & $0.047 \pm 0.018^{\mathrm{b}}$ \\
\hline
\end{tabular}

Additionally, experimental fronds were also transplanted to $2 \mathrm{~m}$ water depth. Those data are given in Table S1 in the Supporting Information. Table shows means \pm SEM $\left(n=5\right.$ for day 0 and 14 , with exceptions of ${ }^{\mathrm{a}} n=2$ and $\left.{ }^{\mathrm{b}} n=4\right)$.

SEM, standard error of the mean; Fuc, fucoxanthin; $\beta$-caro, $\beta$-carotene; VAZ, xanthophyll cycle pigment pool; DPS, de-epoxidation state of xanthophyll cycle pigments. 
$\mathrm{Jan} / \mathrm{Feb}$

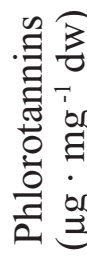

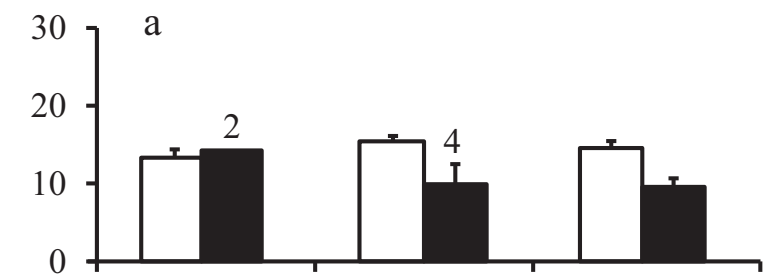
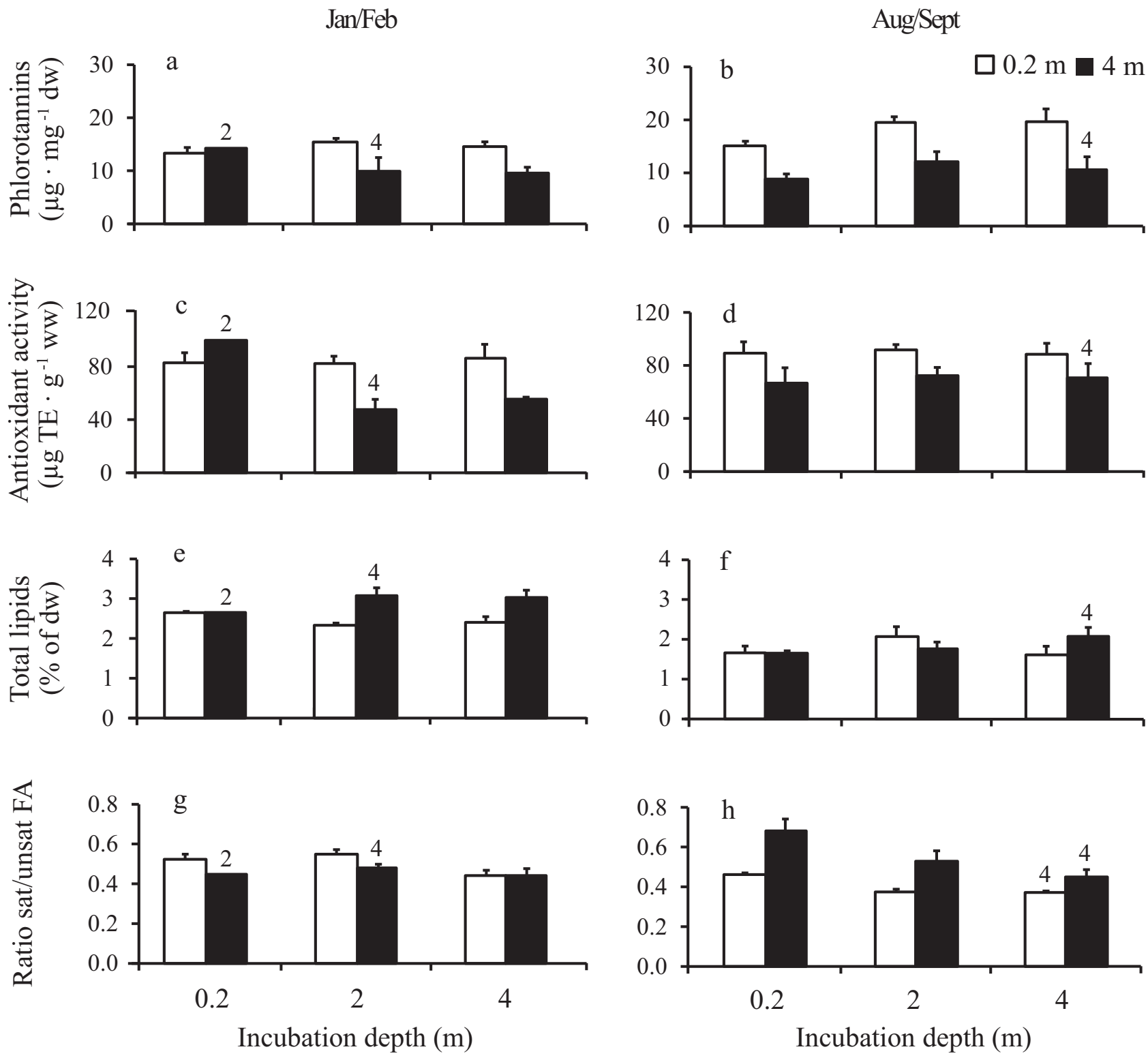

FIG. 1. (a, b) Soluble phlorotannin contents $\left(\mu \mathrm{g} \cdot \mathrm{mg}^{-1} \mathrm{dw}\right.$ ), (c, d) antioxidant activities $\left(\mu \mathrm{g} \mathrm{TE} \cdot \mathrm{g}^{-1}\right.$ ww), (e, f) total lipid contents (\% of $\mathrm{dw})$ and $(\mathrm{g}, \mathrm{h})$ saturated/unsaturated fatty acid ratios (ratio sat/unsat FA) of experimental fronds of Macrocystis pyrifera, collected at two different sampling depths $(0.2$ and $4 \mathrm{~m})$ and transplanted for $14 \mathrm{~d}$ along the depth gradient $(0.2$, 2, and $4 \mathrm{~m})$ during January/February $(\mathrm{Jan} / \mathrm{Feb})$ and August/September (Aug/Sept) 2012. Figure shows means \pm SEM $(n=5$, exceptions are represented by numbers above bars).

during recording. However, those limitations do not affect our general results, as we only accounted for the relative change in parameters.

Pigments: Pigment determination was performed by reversed phase HPLC. The four pooled blade disks from each replicate sample were lyophilized together for $24 \mathrm{~h}$ and pulverized at $4 \mathrm{~m} \cdot \mathrm{s}^{-1}$ for $20 \mathrm{~s}$ in a high-speed benchtop homogenizer (FastPrep ${ }^{\circledR}-24$; MP Biomedicals, Solon, OH, USA). Pigments from 20 to $50 \mathrm{mg}$ dry weight of blade disks were extracted in $1 \mathrm{~mL}$ of ice-cold $90 \%$ acetone for $24 \mathrm{~h}$ at $-20^{\circ} \mathrm{C}$ in the dark. After centrifugation $\left(5 \mathrm{~min}, 4^{\circ} \mathrm{C}\right.$, $13,000 \mathrm{~g}$ ) and filtration through a $45-\mu \mathrm{m}$ nylon syringe filter (Nalgene $^{\circledR}$; Nalge Nunc International, Rochester, NY, USA), HPLC analysis was performed on a LaChromElite ${ }^{\circledR}$ system equipped with a chilled autosampler L-2200 and a DAD detector L-2450 (VWR-Hitachi International GmbH, Darmstadt, Germany). A Spherisorb $^{\circledR}$ ODS-2 column $(25 \mathrm{~cm} \times 4.6 \mathrm{~mm}, 5$ - $\mu \mathrm{m}$ particle size; Waters, Milford, MA, USA) with a LiChrospher ${ }^{\circledR}$ 100-RP-18 guard cartridge was used for the separation of pigments, applying a gradient according to Wright et al. (1991). Peaks were detected at $440 \mathrm{~nm}$ and identified as well as quantified by co-chromatography with standards for Chl $a$ and $c$, fucoxanthin (Fuc), $\beta$ carotene ( $\beta$-caro), violaxanthin, antheraxanthin, and zeaxanthin (DHI Lab Products, Hørsholm, Denmark) using the software EZChrom Elite ver. 3.1.3. (Agilent Technologies, Santa Clara, CA, USA). Pigment contents were expressed as $\mu \mathrm{g} \cdot \mathrm{mg}^{-1}$ dry weight. The de-epoxidation state (DPS) of the 
xanthophyll cycle pigments was calculated as described in Colombo-Pallotta et al. (2006).

Phlorotannins: The total soluble phlorotannin content was determined using the Folin-Ciocalteu method described in Cruces et al. (2012). Purified phloroglucinol (Sigma-Aldrich, Seelze, Germany) was used as a standard. The four pooled blade disks from each replicate sample were lyophilized as described above. Soluble phlorotannins from 10-mg dry weight of blade disks were extracted in $1 \mathrm{~mL}$ of $70 \%$ acetone for $24 \mathrm{~h}$ at $4^{\circ} \mathrm{C}$ under shaking. After centrifugation $(10 \mathrm{~min}$, $\left.4^{\circ} \mathrm{C}, 2,500 \mathrm{~g}\right), 50 \mu \mathrm{L}$ of the supernatant was mixed with $250 \mu \mathrm{L}$ of deionized water $\left(\mathrm{dH}_{2} \mathrm{O}\right), 200 \mu \mathrm{L}$ of $20 \%$ sodium carbonate $\left(\mathrm{NaCO}_{3}\right)$ and $100 \mu \mathrm{L}$ of $2 \mathrm{~N}$ Folin-Ciocalteu reagent (Sigma-Aldrich, Seelze, Germany). After $45 \mathrm{~min}$ of incubation at room temperature in the dark and centrifugation ( $3 \mathrm{~min}$, room temperature, 2,000g), the absorbance was read at $730 \mathrm{~nm}$ using a microplate reader (FLUOstar OPTIMA; BMG Labtech GmbH, Ortenberg, Germany). Soluble phlorotannin contents were estimated from triplicate subsamples, from which one mean was calculated, and defined as $\mu \mathrm{g} \cdot \mathrm{mg}^{-1}$ dry weight.

Antioxidant activity: The antioxidant activity was measured by the free radical DPPH (2,2-diphenyl-1-picrylhydrazyl; Sigma-Aldrich, Seelze, Germany) scavenging method according to Brand-Williams et al. (1995) as modified by Cruces et al. (2012). Trolox (6-hydroxy-2,5,7,8-tetramethylchroman-2carboxylic acid; Sigma-Aldrich, Seelze, Germany) was used as a standard. A $150 \mu \mathrm{M} \mathrm{DPPH*}$ stock solution was prepared in $80 \%$ ethanol. The four pooled blade disks from each replicate sample were ground together in a mortar with liquid nitrogen. Antioxidants from 50-mg wet weight of blade disks were extracted in $1,500 \mu \mathrm{L}$ of $70 \%$ acetone for $24 \mathrm{~h}$ at $4^{\circ} \mathrm{C}$ while shaking in the dark. Afterwards, $22 \mu \mathrm{L}$ of the supernatant and $200 \mu \mathrm{L}$ of the $\mathrm{DPPH}^{*}$ stock solution were directly mixed in a 96-well microplate. After $15 \mathrm{~min}$, the absorbance was measured at $520 \mathrm{~nm}$ using a Multiskan Spectrum microplate photometer (Thermo Fisher Scientific Inc., Waltham, MA, USA). The antioxidant activity was estimated from triplicate subsamples, from which one mean was calculated, and expressed as $\mu \mathrm{g}$ Trolox equivalent (TE) $\cdot \mathrm{g}^{-1}$ wet weight.

Total lipid content and fatty acid composition: The four pooled blade disks from each replicate sample were lyophilized together for $48 \mathrm{~h}$ and pulverized at $1,500 \mathrm{rpm}$ for 1 min with liquid nitrogen in a micro-dismembrator (Typ U, B. Braun Biotech International $\mathrm{GmbH}$, Melsungen, Germany). Total lipids were extracted in dichloromethane: methanol (2:1 per volume) following the methods described by Folch et al. (1957) and Bligh and Dyer (1959). Extracts were pestled and ultrasonicated and total lipid contents were determined gravimetrically after Hagen (2000). For the analysis of FA composition, aliquots of the algal extracts were taken. FAs were converted to their methyl ester derivates (FAMEs) by transesterification with methanol containing $3 \%$ concentrated sulfuric acid for $4 \mathrm{~h}$ at $80^{\circ} \mathrm{C}$. After extracting the FAMEs three times with hexane, their composition was analyzed using a HP 6890 gas chromatograph (Agilent Technologies, Waldbronn, Germany) equipped with a DB-FFAP column (60-m length, $0.25-\mathrm{mm}$ inner diameter, $0.25-\mu \mathrm{m}$ film thickness; Agilent Technologies) operated with temperature programming according to the method of Kattner and Fricke (1986). FAMEs were identified by comparing their retention times with those derived from standards of known composition. Individual FAs are presented as mass percentage of total FAs. Based on the individual FA composition, they are grouped according to their degree of saturation and chain length.

Statistical analysis. To test for differences in temperature and PAR related to the factors sampling time (two levels:
Jan/Feb and Aug/Sept) and incubation depth (two levels for temperature: 0.2 and $6 \mathrm{~m}$, three levels for PAR: 0.2, 2 and $4 \mathrm{~m}$ ), two-factorial analyses of variance (two-way ANOVA) were carried out. When the ANOVA revealed significant differences in PAR, a post-hoc Tukey's honest significant difference (HSD) test was applied. To evaluate differences in $\mathrm{K}_{\mathrm{d}}$ between the two different sampling times (Jan/Feb and Aug/ Sept), an independent Student's $t$-test was conducted. Further, all abiotic data were tested for normality and homogeneity of variances, using Kolmogorov-Smirnov's test and Levene's test, respectively. The software IBM SPSS Statistics 22 (IBM Corporation, Armonk, NY, USA) was used for statistical analyses of abiotic parameters. Critical significance levels of $5 \%$ were used.

Physiological data were analyzed by permutational multivariate analyses of variance (PERMANOVA), based on Euclidean distances. This statistical method was chosen because it allows the testing of complex multivariate experimental designs while maintaining robustness (Anderson 2001). P-values were assessed by using a maximum of 9,999 permutations of the residuals under a reduced model and critical significance levels were set, a priori, at 5\%. A two-factor PERMANOVA was performed on the response variables of initial fronds (Chl a fluorescence: $\mathrm{F}_{\mathrm{v}} / \mathrm{F}_{\mathrm{m}}, \mathrm{ETR}_{\max }, \mathrm{E}_{\mathrm{k}}, \alpha$; pigments: Chl $a$, Chl $c$, Fuc, $\beta$-caro, xanthophyll cycle pigment pool (VAZ), DPS; phlorotannins; antioxidants; total lipids, saturated/unsaturated FA ratio) to test for the effects of the factors sampling time (two levels: Jan/Feb and Aug/Sept; fixed) and sampling depth (two levels: 0.2 and $4 \mathrm{~m}$; fixed). The response variables of experimental fronds exposed to 14-d transplantation (see above) were analyzed by a three-factor PERMANOVA to examine the effects of sampling time, sampling depth, and the additional factor incubation depth (three levels: $0.2,2$, and $4 \mathrm{~m}$; fixed). In case of a significant interaction between all three factors, a posteriori pair-wise comparisons among all pairs of levels of incubation depth were conducted. As PERMANOVA is sensitive to within-factor differences in multivariate dispersions, a permutational analysis of multivariate dispersion (PERMDISP) test was performed for each factor to ensure that multivariate dispersions between groups are homogeneous. Similarity percentage analyses (SIMPER) were carried out to identify the three response variables that contributed most to differences in long- and short-term acclimation patterns. Additionally, principal coordinate analyses (PCO) were used to visualize these differences graphically. Based on the results of the SIMPER analyses, response variables mainly driving the differences were included as overlaying vectors in the plots. Due to differences in units and scales of response variables, all data were normalized prior to analyses. Normalization was done by subtracting the mean from each single variable and dividing this variable by its respective standard deviation. All statistical tests were performed on initial and experimental fronds separately by using PRIMER v6 with PERMANOVA+ add-on (PRIMER-E Ltd, Plymouth, UK).

\section{RESULTS}

Abiotic conditions at various water depths. Differences in PAR among incubation depths were not consistent with time (two-way ANOVA, Ts*Di interaction, $\left.F_{2,279}=37.446, P<0.01\right)$. Regardless of the sampling time, a post-hoc Tukey's HSD test displayed significant differences in levels of PAR between the three incubation depths (each $P<0.001$ ). PAR decreased to $\sim 40 \%$ at $2 \mathrm{~m}$ and $\sim 20 \%$ at $4 \mathrm{~m}$ compared to values measured near the sea surface (two-way ANOVA, 
main effect of incubation depth, $F_{2,279}=290.568$, $P<0.001)$. At all three water depths, irradiance in Aug/Sept (austral winter) was 50\% lower than in Jan/Feb (austral summer; two-way ANOVA, main effect of sampling time, $\left.F_{1,279}=227.172, P<0.001\right)$. Light attenuation $\left(\mathrm{K}_{\mathrm{d}}\right)$ was similar in both sampling times (Student's $t$-test, $t_{93}=-2.143, P=0.053$ ). The differences in seawater temperature between incubation depths were not consistent over time (two-way ANOVA, Ts*Di interaction, $F_{1,14276}=597.210$, $P<0.001)$. Temperature followed a seasonal pattern, with higher values during $\mathrm{Jan} / \mathrm{Feb}$ compared to Aug/Sept (two-way ANOVA, main effect of sampling time, $\left.F_{1,14276}=18,938.275, P<0.001\right)$. However, due to the influence of the Humboldt Current System only minor, but significant depth-related differences in seawater temperatures were observed (two-way ANOVA, main effect of incubation depth, $F_{1,14276}=1,113.983, P<0.001$; Table 1$)$.

Acclimation responses to long-term depth exposure. The differences in the suite of response variables between sampling depths were not consistent over time (two-factor PERMANOVA, Ts*Ds interaction, pseudo- $F_{1,16}=3.000, P=0.028$; Table S3a in the Supporting Information). The PCO plot reflected the results of the PERMANOVA, with the first two axes (PCO1 and PCO2) explaining more than 60\% of variation in the data (Fig. 2a). The plot highlighted a separation of initial fronds, acclimated to the two water depths at both sampling times, with fronds from Jan/Feb $0.2 \mathrm{~m}$, Aug/Sept $0.2 \mathrm{~m}$ and Aug/Sept $4 \mathrm{~m}$ showing slight overlapping, while fronds from Jan/Feb $4 \mathrm{~m}$ were clearly separated from the others (Fig. 2a). The SIMPER analysis (and the vector overlays) indicated that observed differences between both sampling depths were mainly due to variation in variable Chl $a$ fluorescence of PSII $\left(\mathrm{ETR}_{\max }, \mathrm{E}_{\mathrm{k}}, \alpha\right)$, Chl $c$, DPS and phlorotannins (Table S4a in the Supporting Information; Fig. 2a). In addition to those parameters, mainly total lipids and saturated/unsaturated (sat/ unsat) FA ratio seemed to drive differences in longterm acclimation to various water depths between both sampling times (Table S4b; Fig. 2a). This is also obvious from individual comparisons of the respective response variables between the differ-
FIG. 2. Principal coordinate analysis (PCO) plots for (a) initial fronds (Day 0) and (b) experimental fronds (Day 14) of Macrocystis pyrifera, based on Euclidean distances. Labels above the symbols indicate incubation depths $(0.2,2$, and $4 \mathrm{~m})$, to which experimental fronds were exposed for $14 \mathrm{~d}$. Vector overlays represent the response variables (alpha, initial linear slope of photosynthesis vs. irradiance curve; antioxidants; Chl $c$; DPS, de-epoxidation state of xanthophyll cycle pigments; $\mathrm{E}_{\mathrm{k}}$, saturating irradiance; $\mathrm{ETR}_{\max }$, maximum electron transport rate; Fuc, fucoxanthin; $F_{v} / F_{m}$, maximum quantum yield; phlorotannins; ratio sat/unsat FA, saturated/ unsaturated fatty acid ratio; total lipids) mainly driving the observed differences, according to SIMPER analyses Table S4 in the Supporting Information.
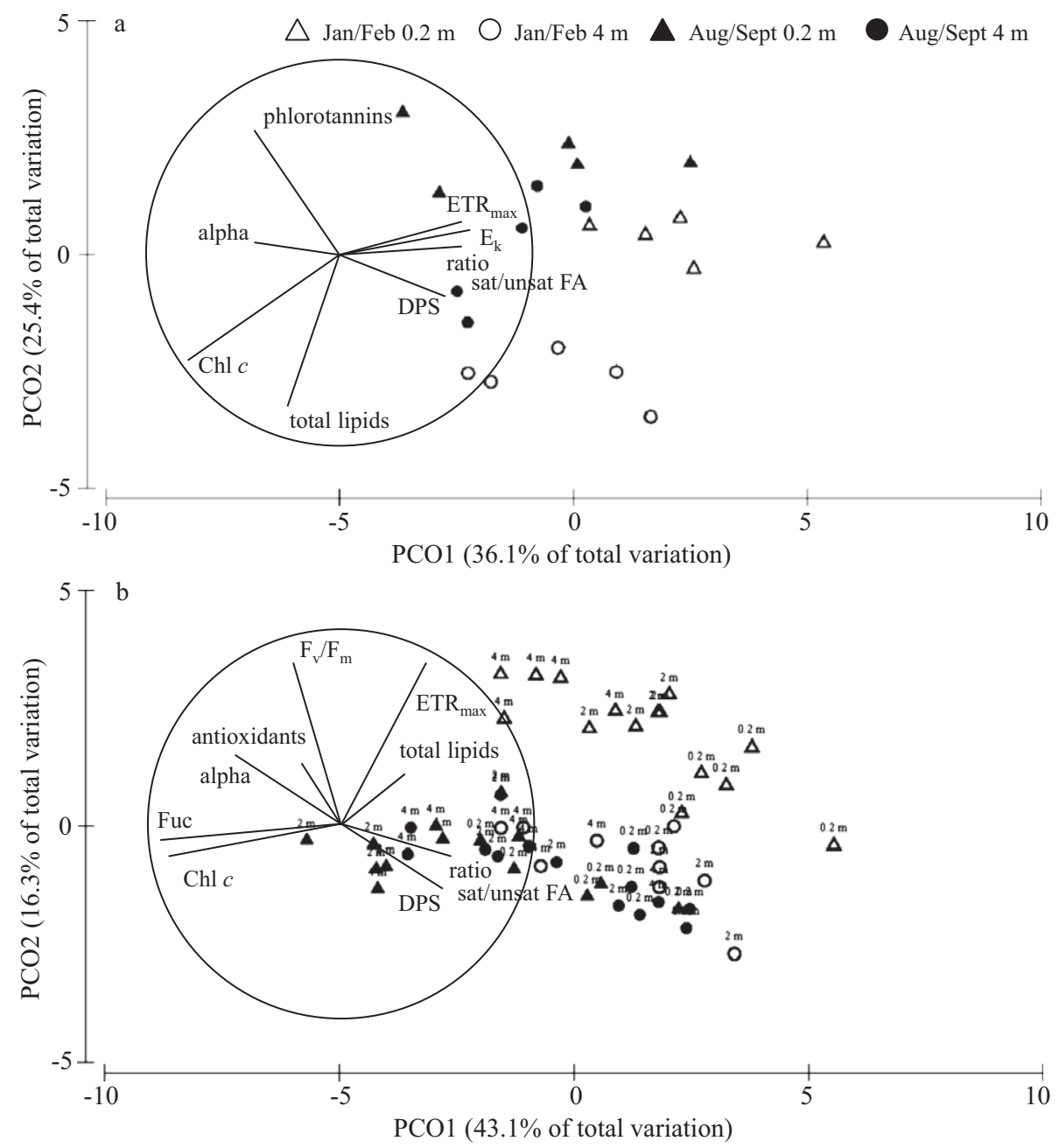
ent sampling times and depths, with initial fronds displaying higher values of $\mathrm{ETR}_{\max }$ and $\mathrm{E}_{\mathrm{k}}$ and lower Chl $c$ contents at $0.2 \mathrm{~m}$ depth than at $4 \mathrm{~m}$ (Tables 2 and 3). Further, initial fronds from $0.2 \mathrm{~m}$ in Aug/Sept showed two times higher soluble phlorotannin contents, those from $4 \mathrm{~m}$ in Jan/Feb and those from $0.2 \mathrm{~m}$ in Jan/Feb exhibited one and a half times higher total lipid contents and sat/ unsat FA ratios than all other fronds, respectively (Fig. 3, a, c and d). Although levels of other photosynthetic pigments and antioxidants also differed in initial fronds from various sampling times and depths (Table 3; Fig. 3b), these response variables contributed only little to the observed differences in long-term acclimation responses (Table S4a and b; Fig. 2a).

With respect to the FA composition of initial kelp fronds, 15 different FAs (five saturated and ten unsaturated FAs) were detected. FA 16:0 was the most abundant saturated FA and FA 20:4(n-6) the dominant unsaturated FA. Other principal FAs were 14:0, 18:1(n-9), 18:4(n-3) and 20:5(n-3) (for details see Table S5 in the Supporting Information).

Acclimation responses to short-term depth exposure. During the transplantation experiment, experimental kelp fronds, sampled at $0.2 \mathrm{~m}$ or $4 \mathrm{~m}$ in Jan/ Feb or Aug/Sept, were able to survive and showed positive growth, but clear patterns in relation to the three incubation depths were absent. Differences in the suite of response variables among incubation depth were not consistent with initial sampling depth or time (three-factor PERMANOVA, Ts*Ds*Di interaction, $\quad$ pseudo- $F_{2,41}=2.084, \quad P=0.019$;
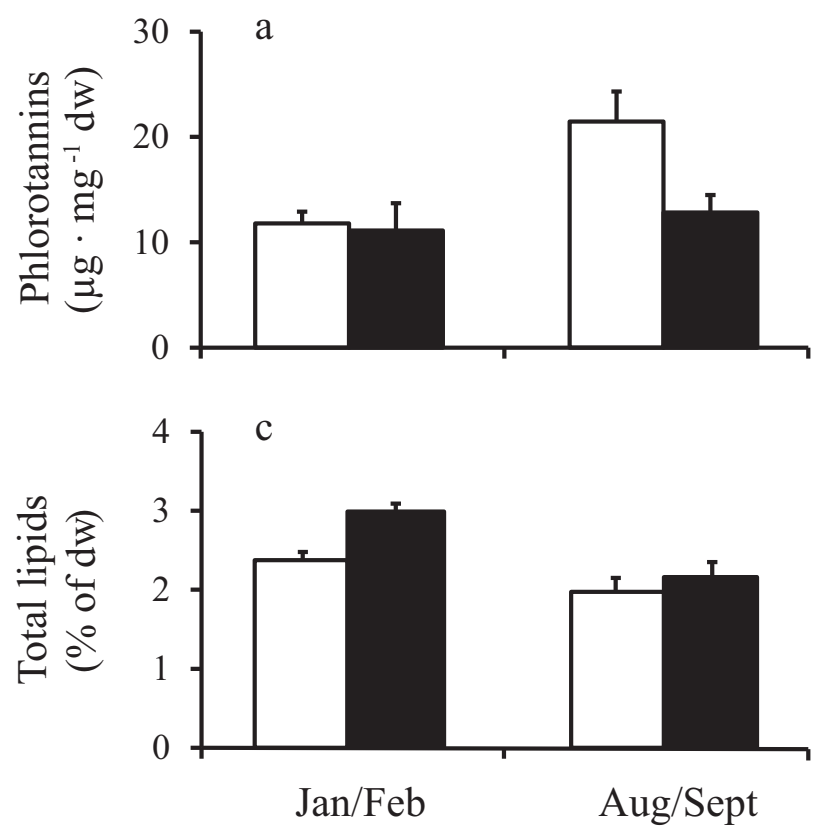

Table S3b). An a posteriori pair-wise comparison based on permutation for this interaction among all pairs of the three-level factor incubation depth displayed differences between fronds from various sampling times and depths (Table S6 in the Supporting Information). Kelp fronds collected at $0.2 \mathrm{~m}$ depth in Jan/Feb showed significant differences after transplantation along the depth gradient for $14 \mathrm{~d}$ among all possible pairs of incubation depth $(0.2 \mathrm{~m}$ vs. $2 \mathrm{~m}$, $0.2 \mathrm{~m}$ vs. $4 \mathrm{~m}$ and $2 \mathrm{~m}$ vs. $4 \mathrm{~m}$ ). In contrast, the experimental fronds originating from $4 \mathrm{~m}$ depth in Jan/Feb differed only significantly between the most extreme incubation depths $(0.2 \mathrm{~m}$ vs. $4 \mathrm{~m})$. Kelp fronds from both $0.2 \mathrm{~m}$ and $4 \mathrm{~m}$ in Aug/Sept revealed significant differences between shallow waters $(0.2 \mathrm{~m})$ and the two deeper incubation depths $(0.2 \mathrm{~m}$ vs. $2 \mathrm{~m}$ and $0.2 \mathrm{~m}$ vs. $4 \mathrm{~m}$; Table S6). The PCO plot, which explained $\sim 60 \%$ of the variation in the data in the two-dimensional space (PCO1 and PCO2), illustrates the results of the pair-wise comparisons (Fig. 2b). Consequently, experimental fronds collected at $0.2 \mathrm{~m}$ depth in Jan/Feb were clearly distinguishable from the other fronds and revealed a distinct separation with respect to acclimation to the three incubation depths. All other experimental fronds were grouped closer together and showed a less clear separation by acclimation among the incubation depths (Fig. 2b).

The SIMPER analysis (and the vector overlays) suggested that differences among acclimation to incubation depths in Jan/Feb were mainly due to changes in variable Chl $a$ fluorescence $\left(\mathrm{F}_{\mathrm{v}} / \mathrm{F}_{\mathrm{m}}, \alpha\right)$, DPS and antioxidants, whereas those in Aug/Sept
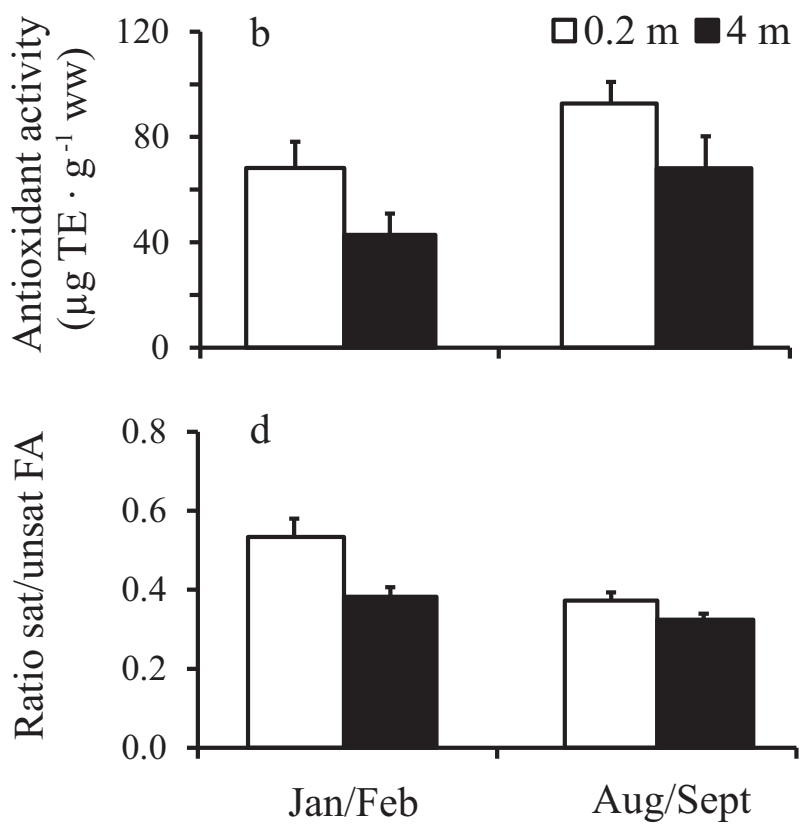

Fig. 3. (a) Soluble phlorotannin contents $\left(\mu \mathrm{g} \cdot \mathrm{mg}^{-1} \mathrm{dw}\right)$, (b) antioxidant activities $\left(\mu \mathrm{g} \mathrm{TE} \cdot \mathrm{g}^{-1} \mathrm{ww}\right)$, (c) total lipid contents (\% of $\mathrm{dw}$ ) and (d) saturated/unsaturated fatty acid ratios (ratio sat/unsat FA) of initial fronds of Macrocystis pyrifera, collected at two different water depths $(0.2$ and $4 \mathrm{~m}$ ) during January/February (Jan/Feb) and August/September (Aug/Sept) 2012. Figure shows means \pm SEM $(n=5)$. 
resulted mainly from changes in pigments (Chl c, Fuc), DPS and sat/unsat FA ratio (Table S4c; Fig. 2b). Changes in variable Chl $a$ fluorescence $\left(\mathrm{F}_{\mathrm{v}} / \mathrm{F}_{\mathrm{m}}, \mathrm{ETR}_{\max }\right)$, DPS, antioxidants, total lipids, and sat/unsat FA ratio accounted further for the greatest proportion of differences in short-term acclimation along the depth gradient between both sampling times (Table S4d; Fig. 2b). This can also be seen by one-to-one comparisons of the respective response variables between the various incubation depths, with experimental fronds from surface waters exhibiting lower $\mathrm{Chl} c$ and Fuc contents and higher DPS than those from deeper waters (Table 3 and Table S1). Further, experimental fronds, transplanted from 4 to $0.2 \mathrm{~m}$ depth in Jan/Feb, showed an almost two and a half-fold increase in antioxidant activity compared to initial values (Figs. 1c and $3 \mathrm{~b})$. Related to the sat/unsat FA ratio, the strongest acclimation response was found in kelp fronds collected at $4 \mathrm{~m}$ depth in Aug/Sept. The sat/unsat FA ratio of these fronds was highest at $0.2 \mathrm{~m}$ incubation depth and decreased with increasing depth (Fig. 1h). In addition to the change in the degree of FA saturation, an alteration of FA chain length was observed. Experimental kelp fronds, transplanted from 4 to $0.2 \mathrm{~m}$ depth in Aug/Sept, exhibited a decrease in shorter-chain FAs $(14,15$ and 16 $\mathrm{C}$ atoms) and an increase in longer-chain FAs (17, 18 , and $20 \mathrm{C}$ atoms) during the experimental duration of $14 \mathrm{~d}$ (Fig. 4). Although amounts of other photosynthetic pigments and phlorotannins also varied in experimental fronds with respect to incubation depth (Table 3 and Table S1; Fig. 1a and b), these parameters did not primarily account for the observed differences in short-term acclimation responses (Table S4c and d; Fig. 2b).

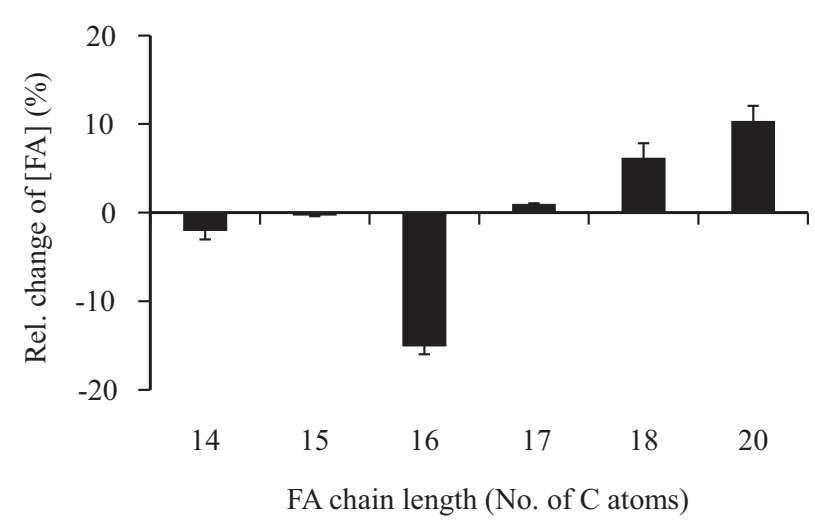

FIG. 4. Relative change in fatty acid (FA) concentrations (\%), grouped by different chain lengths, of experimental fronds of Macrocystis pyrifera, transplanted from 4 to $0.2 \mathrm{~m}$ depth for $14 \mathrm{~d}$ during August/September 2012. Figure shows means \pm SEM $(n=4-5)$.

\section{DISCUSSION}

Overall, the results of this study confirm the high acclimation potential of $M$. pyrifera to the prevailing abiotic conditions along a depth gradient, but they should be interpreted with the understanding that depth effects are potentially influenced by spatial differences in origin of the experimental source plants. We observed both advantageous acclimation strategies to various water depths between different sampling times (long-term acclimation responses) as well as more rapid physiologically favorable adjustments during $14 \mathrm{~d}$ of transplantation to different depths (short-term acclimation responses). However, in contrast to other studies (e.g., $0-9 \mathrm{~m}$ in Gerard 1986 or $0-18 \mathrm{~m}$ in Colombo-Pallotta et al. 2006), we worked with a comparatively small depth gradient $(0.2-4 \mathrm{~m})$. Interestingly, the physiological adjustments of $M$. pyrifera were evident even at this smaller scale, which further illustrates the enormous acclimation capacity of this kelp species.

Acclimation responses to long-term depth exposure. With respect to long-term acclimation responses, initial fronds of $M$. pyrifera, growing at various water depths in Jan/Feb or Aug/Sept, exhibited different physiological acclimation states due to the respective conditions of solar radiation and temperature. Statistical analyses suggested that adjustments in variable Chl $a$ fluorescence of PSII, photosynthetic pigments, phlorotannins, total lipids, and the degree of FA saturation mainly contributed to these observed differences. Initial fronds followed the well-known pattern of photoacclimation to various light conditions along the depth gradient by displaying higher values of $\mathrm{ETR}_{\max }$ and $\mathrm{E}_{\mathrm{k}}$ and lower concentrations of the antenna pigment Chl $c$ in shallow than in deep waters (Wheeler 1980, Smith and Melis 1987, Reiskind et al. 1989). Thus, photosynthesis of $M$. pyrifera occurring in greater water depths is already saturated at lower light intensities (Reiskind et al. 1989) and the observed variations in Chl $c$ concentrations allow the alga to absorb more photons under lower light intensities in deeper waters (e.g., Wheeler 1980, Smith and Melis 1987). Consequently, the observed acclimation responses are beneficial for $M$. pyrifera growing under the different environmental conditions at various water depths with different light regimes in Jan/Feb and Aug/Sept.

Higher soluble phlorotannin contents of initial fronds from $0.2 \mathrm{~m}$ depth compared to $4 \mathrm{~m}$ in Aug/ Sept might indicate the protective role of these compounds against the adverse effects of high solar radiation near the water surface (Schoenwaelder 2002). Surprisingly, this finding could only be observed in fronds from Aug/Sept but not in those from Jan/Feb and is in contrast to the seasonal pattern of phlorotannin levels found in the other large kelp, Durvillaea antarctica, which frequently occurs 
together with $M$. pyrifera along the Chilean coastline (Tala et al. 2013). Why M. pyrifera reacted contrarily to this often observed pattern remains unresolved.

Initial fronds probably growing under lower water temperatures and solar radiation (Jan/Feb $4 \mathrm{~m}$, Aug/Sept 0.2 and $4 \mathrm{~m}$ ) exhibited one and a half times lower sat/unsat FA ratios than those exposed to the highest temperature and solar radiation levels (Jan/Feb $0.2 \mathrm{~m})$. We suggest that this enhanced degree of unsaturation might act as compensation for the decrease in membrane fluidity, which is induced by low temperature and possibly also low light (Buchanan et al. 2000). Increased FA desaturation as a response to a drop in temperature has been observed already in several brown algal species (e.g., Fucus vesiculosus, Laminaria japonica, Sargassum pallidum; Pohl and Zurheide 1979, Sanina et al. 2008) and those changes with respect to differences in abiotic conditions play a key role in the readjustment of cellular membranes, so that these can remain operative (Thompson 1996). This is especially important for thylakoid membranes, which contain the photosynthetic apparatus. To maintain a high photosynthetic capacity, degraded proteins must be removed and de-novo synthesized proteins must be re-integrated into the reaction centers (i.e., D1 protein turnover). This process takes place via lateral diffusion through the thylakoid membranes and is highly dependent on membrane fluidity (Becker et al. 2010 and references therein).

Acclimation responses to short-term depth exposure. Overall, after $14 \mathrm{~d}$ of transplantation along a depth gradient, experimental fronds of $M$. pyrifera collected at various sampling times and depths adjusted their physiological states to the new abiotic conditions, resulting in differences in short-term acclimation responses to solar radiation and temperature levels along the depth gradient. These results should be interpreted with the understanding that multiple abiotic factors might have influenced the acclimation responses of $M$. pyrifera simultaneously. In this study, we only concentrated on differences in irradiance of PAR and water temperature along the depth gradient. Other factors, like nutrient concentrations, could also vary at the various water depths and thereby affect algal ecophysiology (Buschmann et al. 2014b), although previous studies did not find nitrogen limitation in sporophytes of $M$. pyrifera in waters of northern-central Chile (e.g., Rothäusler et al. 2011b), which are rich in nutrients, particularly nitrogen, without clear vertical gradients (Moraga and Olivares 1993). In particular, kelp fronds collected at $0.2 \mathrm{~m}$ in Jan/Feb developed physiological states that varied clearly between all three incubation depths. We propose that this differential acclimation might be due to the maximum amplitude of changing solar radiation and temperature conditions along the depth gradient in Jan/Feb (Table 1). In contrast, kelp fronds from $4 \mathrm{~m}$ sampling depth in Jan/Feb did not show this pronounced differentiation after transplantation, despite experiencing the same amplitude of change in abiotic conditions, only in the opposite direction. We presume that transient stress caused by photoinhibition right after transplantation from deep $(4 \mathrm{~m})$ to surface $(0.2 \mathrm{~m})$ solar radiations, as indicated by measurements of $\mathrm{F}_{\mathrm{v}} / \mathrm{F}_{\mathrm{m}}$ on day 7 of the experiment (data not shown), might be responsible for this observation. This interpretation is supported by the almost two and a half-fold increase in antioxidant activity, which also is plausible, because antioxidants are known to protect the photosynthetic apparatus against permanent photodamage by scavenging ROS, formed at the photosynthetic electron transport chain under intense solar radiation conditions (Bischof and Rautenberger 2012). Similar results were reported in a study by Cruces et al. (2012) on the effects of temperature and UV on the radical scavenging activity in South Pacific kelps. They reported maximum scavenging activity after UV-exposure at $20^{\circ} \mathrm{C}$. These abiotic conditions are comparable to those prevailing in surface waters during Jan/Feb in our study.

Our results suggested that differences in shortterm acclimation responses were mainly driven by changes in Chl $a$ fluorescence of PSII, photosynthetic pigments, total lipids, and the degree of FA saturation in addition to the shifts in antioxidant activities. This response was similar to the adjustments found during long-term acclimation, in that experimental fronds responded according to the classical pattern of photoacclimation along a depth gradient by exhibiting increased Chl $c$ and Fuc contents at greater water depths in order to adjust antenna sizes to the new prevailing irradiances (e.g., Wheeler 1980, Smith and Melis 1987). Contrarily, de-epoxidation states of the xanthophyll cycle pigments were greatest in shallow waters and decreased with depth. Similar results were detected by Colombo-Pallotta et al. (2006) and García-Mendoza and Colombo-Pallotta (2007). Since xanthophyll cycle pigment de-epoxidation can be activated within several minutes, this protection mechanism of the photosynthetic apparatus in terms of excess light energy dissipation via NPQ might be especially important during abrupt changes of potentially stressful environmental conditions (Yamamoto et al. 1962), which are more pronounced in surface waters than at greater depths (e.g., Gerard 1984, Hanelt 1996). Additionally, this protection mechanism would be especially important when algae detach from the primary substratum and float to the sea surface (Rothäusler et al. 2011a). However, although shifts in variable Chl a fluorescence of PSII accounted for a great proportion of differences in short-term acclimation, these parameters were quite variable and did not show a consistent trend according to incubation depth. The susceptibility of PAM fluorometry to various factors (e.g., variable weather 
conditions during measuring days, use of different blade parts for measurements due to grazing effects or losses of replicates due to strong wave action) might be responsible for the observed variability (Edwards and Kim 2010). Overall, high maximum quantum yields $(\sim 90 \%-115 \%$ of initial values) indicated that the kelp fronds were not continuously stressed and showed no signs of photodamage on day 14 of the experiments. However, $M$. pyrifera, which had been sampled at $4 \mathrm{~m}$ depth, showed unexpectedly high increases of $\mathrm{ETR}_{\max }$ and $\mathrm{E}_{\mathrm{k}}$ ( 4- to 7-fold increases) after transplantation to the three water depths in Jan/Feb and Aug/Sept. One possible explanation might be the loss of self-shading and continuous vertical displacement of blade layers, which typically occur within a kelp forest (Gerard 1986), during our transplantation experiment.

Experimental fronds responded to the transplantation from $4 \mathrm{~m}$ to $0.2 \mathrm{~m}$ water depth with a rise in the degree of FA saturation (2-fold increase of sat/ unsat FA ratio) and a switch from shorter- to longer-chain FAs. Interestingly, this strong response occurred only in Aug/Sept, but not in Jan/Feb. One possible explanation for this finding is that in Aug/Sept the kelp had to cope with a particularly challenging combination of abiotic conditions (high PAR at low temperature) in surface waters. Since during Aug/Sept, temperature barely changed with water depth, we suggest that differences in PAR levels might be the major factor for the observed changes in FA composition, but this assumption has to be verified in further laboratory studies (see Conclusions and outlook). Although light-induced variation in FAs of macroalgae is a frequently observed phenomenon (e.g., Pettitt and Harwood 1989, Levy et al. 1992), its implication is not entirely clear and less plausible than the temperature-induced sensitivity of membrane fluidity.

Conclusions and outlook. Macrocystis pyrifera was capable of adjusting its physiological status to various conditions of solar radiation and temperature along a depth gradient on a long-term and shortterm timescale, in which the latter might be especially important in the context of detachment and rafting. Our results indicated that acclimation strategies in $M$. pyrifera can vary on different temporal scales, with phlorotannins being important during long-term acclimation and antioxidants playing a crucial role during short-term acclimation. Furthermore, adjustments in total lipids and FA compositions apparently contribute to acclimation strategies to an extent comparable to other response variables (variable Chl $a$ fluorescence, pigments, phlorotannins, antioxidants). To our knowledge, this is the first study showing the importance of lipid adjustments for acclimation in M. pyrifera. However, with the chosen experimental set-up, it is difficult to disentangle which abiotic factor (solar radiation, temperature, or others) is responsible for the observed physiological changes, especially with respect to FA composition. Future fully controlled field or laboratory experiments are needed to elucidate the relative influences of the abiotic parameters. Further, future studies should focus on changes in FA composition within different lipid classes of $M$. pyrifera, which would allow identification of which specific membranes (e.g., thylakoid membranes) are primarily affected by the observed adjustments in FAs.

Funding of this study was provided by the FONDECYT grant 1100749 to M.T., F.T. and I.G. We would like to thank the members of the BEDIM laboratory (UCN) for their help in the field and during the experiments, Britta Meyer-Schlosser for technical support in pigment analysis (HPLC), Petra Wencke for competent assistance with the lipid evaluations and Purisima Rivas for analysis of antioxidant activity. Furthermore, we are grateful to the anonymous reviewers for many constructive comments which helped to improve this manuscript.

Anderson, M. J. 2001. A new method for non-parametric multivariate analysis of variance. Austral Ecol. 26:32-46.

Becker, S., Graeve, M. \& Bischof, K. 2010. Photosynthesis and lipid composition of the Antarctic endemic rhodophyte Palmaria decipiens: effects of changing light and temperature levels. Polar Biol. 33:945-55.

Bischof, K. \& Rautenberger, R. 2012. Seaweed responses to environmental stress: reactive oxygen and antioxidative strategies. In Wiencke, C. \& Bischof, K. [Eds.] Seaweed Biology, Ecological Studies 219. Springer-Verlag, Berlin, Heidelberg, Germany, pp. 109-34.

Bligh, E. G. \& Dyer, W. J. 1959. A rapid method of total lipid extraction and purification. Can. J. Biochem. Physiol. 37:911-7.

Brand-Williams, W., Cuvelier, M. E. \& Berset, C. 1995. Use of a free radical method to evaluate antioxidant activity. Lebensm. Wiss. Technol. 28:25-30.

Buchanan, B. B., Gruissem, W. \& Jones, R. L. 2000. Biochemistry \& Molecular Biology of Plants. American Society of Plant Physiologists, Rockville, Maryland, 1367 pp.

Buschmann, A. H., Pereda, S. V., Varela, D. A., RodríguezMaulén, J., López, A., González-Carvajal, L., Schilling, M., Henríquez-Tejo, E. A. \& Hernández-González, M. C. 2014b. Ecophysiological plasticity of annual populations of giant kelp (Macrocystis pyrifera) in a seasonally variable coastal environment in the Northern Patagonian Inner Seas of Southern Chile. J. Appl. Phycol. 26:837-47.

Buschmann, A. H., Prescott, S., Potin, P., Faugeron, S., Vásquez, J. A., Camus, C., Infante, J., Hernández-González, M. C., Gutíerrez, A. \& Varela, D. A. 2014a. The status of kelp exploitation and marine agronomy, with emphasis on Macrocystis pyrifera in Chile. Adv. Bot. Res. 71:161-88.

Buschmann, A. H., Vásquez, J. A., Osorio, P., Reyes, E., Filún, L., Hernández-González, M. C. \& Vega, A. 2004. The effect of water movement, temperature and salinity on abundance and reproductive patterns of Macrocystis spp. (Phaeophyta) at different latitudes in Chile. Mar. Biol. 145:849-62.

Colombo-Pallotta, M. F., García-Mendoza, E. \& Ladah, L. B. 2006. Photosynthetic performance, light absorption, and pigment composition of Macrocystis pyrifera (Laminariales, Phaeophyceae) blades from different depths. J. Phycol. 42:1225-34.

Cruces, E., Huovinen, P. \& Gómez, I. 2012. Phlorotannin and antioxidant responses upon short-term exposure to UV radiation and elevated temperature in three South Pacific kelps. Photochem. Photobiol. 88:58-66.

Dean, T. A. 1985. The temporal and spatial distribution of underwater quantum irradiation in a Southern California kelp forest. Estuar. Coast. Shelf Sci. 21:835-44. 
Edwards, M. S. \& Kim, K. Y. 2010. Diurnal variation in relative photosynthetic performance in giant kelp Macrocystis pyrifera (Phaeophyceae, Laminariales) at different depths as estimated using PAM fluorometry. Aquat. Bot. 92:119-28.

Folch, J., Lees, M. \& Sloane Stanley, G. H. 1957. A simple method for the isolation and purification of total lipides from animal tissues. J. Biol. Chem. 226:497-509.

García-Mendoza, E. \& Colombo-Pallotta, M. F. 2007. The giant kelp Macrocystis pyrifera presents a different nonphotochemical quenching control than higher plants. New Phytol. 173: 526-36.

Garreaud, R. D., Rutllant, J. A., Muñoz, R. C., Rahn, D. A., Ramos, M. \& Figueroa, D. 2011. VOCALS-CUpEx: the Chilean upwelling experiment. Atmos. Chem. Phys. 11:2015-29.

Gerard, V. A. 1984. The light environment in a giant kelp forest: influence of Macrocystis pyrifera on spatial and temporal variability. Mar. Biol. 84:189-95.

Gerard, V. A. 1986. Photosynthetic characteristics of giant kelp (Macrocystis pyrifera) determined in situ. Mar. Biol. 90:473-82.

Graham, M. H., Vásquez, J. A. \& Buschmann, A. H. 2007. Global ecology of the giant kelp Macrocystis: from ecotypes to ecosystems. Oceanogr. Mar. Biol. 45:39-88.

Hagen, W. 2000. Lipids. In Harris, R. P., Wiebe, P. H., Lenz, J., Skjoldal, H. R. \& Huntley, M. [Eds.] ICES Zooplankton Methodology Manual. Academic Press, San Diego, California, pp. 113-9.

Hanelt, D. 1996. Photoinhibition of photosynthesis in marine macroalgae. Sci. Mar. 60:243-8.

Hormazabal, S. \& Shaffer, G. 2002. Tropical Pacific control of intraseasonal oscillations off Chile by way of oceanic and atmospheric pathways. Geophys. Res. Lett. 29:5-1-4.

Huovinen, P. \& Gómez, I. 2011. Spectral attenuation of solar radiation in Patagonian fjord and coastal waters and implications for algal photobiology. Cont. Shelf Res. 31:254-9.

Jassby, A. D. \& Platt, T. 1976. Mathematical formulation of the relationship between photosynthesis and light for phytoplankton. Limnol. Oceanogr. 21:540-7.

Kattner, G. \& Fricke, H. S. G. 1986. Simple gas-liquid chromatographic method for the simultaneous determination of fatty acids and alcohols in wax esters of marine organisms. J. Chromatogr. 361:263-8.

Khotimchenko, S. V., Vaskovsky, V. E. \& Titlyanova, T. V. 2002. Fatty acids of marine algae from the Pacific coast of North California. Bot. Mar. 45:17-22.

Kirk, J. T. O. 1994. Light and Photosynthesis in Aquatic Ecosystems, 2nd edn. Cambridge University Press, Cambridge, UK, 509 pp.

Levy, I., Maxim, C. \& Friedlander, M. 1992. Fatty acid distribution among some red algal macrophytes. J. Phycol. 28:299-304.

Macaya, E. C., Boltaña, S., Hinojosa, I. A., Macchiavello, J. E., Valdivia, N. A., Vásquez, N. R., Buschmann, A. H., Vásquez, J. A., Vega, J. M. A. \& Thiel, M. 2005. Presence of sporophylls in floating kelp rafts of Macrocystis spp. (Phaeophyceae) along the Chilean Pacific coast. J. Phycol. 41:913-22.

Macaya, E. C. \& Zuccarello, G. C. 2010. Genetic structure of the giant kelp Macrocystis pyrifera along the southeastern Pacific. Mar. Ecol. Prog. Ser. 420:103-12.

Moraga, J. \& Olivares, J. 1993. Condiciones oceanográficas del área próxima a la costa frente a Coquimbo, Chile. Serie Ocasional, Universidad Católica del Norte 2:125-40.

Nelson, M. M., Phleger, C. F. \& Nichols, P. D. 2002. Seasonal lipid composition in macroalgae of the Northeastern Pacific Ocean. Bot. Mar. 45:58-65.

North, W. J. 1971. Introduction and background. In North, W. J. [Ed.] The Biology of Giant Kelp Beds (Macrocystis) in California. Nova Hedwigia 32:1-97.

North, W. J. 1994. Review of Macrocystis biology. In Akatsuka, I. [Ed.] Biology of Economic Algae. SPB Academic Publishing, The Hague, The Netherlands, pp. 447-527.

Pérez-Matus, A., Ferry-Graham, L. A., Cea, A. \& Vásquez, J. A. 2007. Community structure of temperate reef fishes in kelpdominated subtidal habitats of northern Chile. Mar. Freshw. Res. 58:1069-85.
Pettitt, T. R. \& Harwood, J. L. 1989. Alterations in lipid metabolism caused by illumination of the marine red algae Chondrus crispus and Polysiphonia lanosa. Phytochemistry 28:3295-300.

Pettitt, T. R., Jones, A. L. \& Harwood, J. L. 1989. Lipid metabolism in the marine red algae Chondrus crispus and Polysiphonia lanosa as modified by temperature. Phytochemistry 28:2053-8.

Pohl, P. \& Zurheide, F. 1979. Fatty acids and lipids of marine algae and the control of their biosynthesis by environmental factors. In Hoppe, H. A., Levring, T. \& Tanaka, Y. [Eds.] Marine Algae in Pharmaceutical Science. Walter de Gruyter, Berlin, Germany, pp. 473-523.

Reiskind, J. B., Beer, S. \& Bowes, G. 1989. Photosynthesis, photorespiration and ecophysiological interactions in marine macroalgae. Aquat. Bot. 34:131-52.

Rothäusler, E., Gómez, I., Hinojosa, I. A., Karsten, U., Miranda, L., Tala, F. \& Thiel, M. 2011b. Kelp rafts in the Humboldt Current: interplay of abiotic and biotic factors limit their floating persistence and dispersal potential. Limnol. Oceanogr. 56:1751-63.

Rothäusler, E., Gómez, I., Hinojosa, I. A., Karsten, U., Tala, F. \& Thiel, M. 2009. Effect of temperature and grazing on growth and reproduction of floating Macrocystis spp. (Phaeophyceae) along a latitudinal gradient. J. Phycol. 45:547-59.

Rothäusler, E., Gómez, I., Karsten, U., Tala, F. \& Thiel, M. 2011a. Physiological acclimation of floating Macrocystis pyrifera to temperature and irradiance ensures long-term persistence at the sea surface at mid-latitudes. J. Exp. Mar. Biol. Ecol. 405:33-41.

Rothäusler, E., Gutow, L. \& Thiel, M. 2012. Floating seaweeds and their communities. In Wiencke, C. \& Bischof, K. [Eds.] Seaweed Biology, Ecological Studies 219. Springer-Verlag, Berlin, Heidelberg, Germany, pp. 359-80.

Sanina, N. M., Goncharova, S. N. \& Kostetsky, E. Y. 2008. Seasonal changes of fatty acid composition and thermotropic behavior of polar lipids from marine macrophytes. Phytochemistry 69:1517-27.

Schmid, M., Guihéneuf, F. \& Stengel, D. B. 2014. Fatty acid contents and profiles of 16 macroalgae collected from the Irish Coast at two seasons. J. Appl. Phycol. 26:451-63.

Schoenwaelder, M. E. A. 2002. Physode distribution and the effect of thallus sunburn in Hormosira banksii (Fucales, Phaeophyceae). Bot. Mar. 45:262-6.

Schoenwaelder, M. E. A. \& Clayton, M. N. 1998. Secretion of phenolic substances into the zygote wall and cell plate in embryos of Hormosira and Acrocarpia (Fucales, Phaeophyceae). J. Phycol. 34:969-80.

Schreiber, U., Bilger, W. \& Neubauer, C. 1994. Chlorophyll fluorescence as a non-intrusive indicator for rapid assessment of in vivo photosynthesis. Ecol. Stud. 100:49-70.

Smith, B. M. \& Melis, A. 1987. Photosystem stoichiometry and excitation distribution in chloroplasts from surface and minus 20 meter blades of Macrocystis pyrifera, the giant kelp. Plant Physiol. 84:1325-30.

Swanson, A. K. \& Fox, C. H. 2007. Altered kelp (Laminariales) phlorotannins and growth under elevated carbon dioxide and ultraviolet-B treatments can influence associated intertidal food webs. Glob. Change Biol. 13:1696-709.

Tala, F., Gómez, I., Luna-Jorquera, G. \& Thiel, M. 2013. Morphological, physiological and reproductive conditions of rafting bull kelp (Durvillaea antarctica) in northern-central Chile $\left(30^{\circ}\right.$ S). Mar. Biol. 160:1339-51.

Tapia, F. J., Largier, J. L., Castillo, M., Wieters, E. A. \& Navarrete, S. A. 2014. Latitudinal discontinuity in thermal conditions along the nearshore of central-northern Chile. PLoS ONE 9: e110841.

Thiel, M. \& Haye, P. A. 2006. The ecology of rafting in the marine environment. III. Biogeographical and evolutionary consequences. Oceanogr. Mar. Biol. 44:323-429.

Thompson, G. A. Jr 1996. Lipids and membrane functions in green algae. Biochim. Biophys. Acta 1302:17-45.

Towle, D. W. \& Pearse, J. S. 1973. Production of the giant kelp, Macrocystis, estimated by in situ incorporation of ${ }^{14} \mathrm{C}$ in polyethylene bags. Limnol. Oceanogr. 18:155-9. 
Villegas, M. J., Laudien, J., Sielfeld, W. \& Arntz, W. E. 2008. Macrocystis integrifolia and Lessonia trabeculata (Laminariales; Phaeophyceae) kelp habitat structures and associated macrobenthic community off northern Chile. Helgol. Mar. Res. 62:S33-43.

Westermeier, R., Murúa, P., Patiño, D. J., Muñoz, L. \& Müller, D. G. 2014. Giant kelp (Macrocystis) fishery in Atacama (Northern Chile): biological basis for management of the integrifolia morph. J. Appl. Phycol. 26:1071-9.

Wheeler, W. N. 1980. Pigment content and photosynthetic rate of the fronds of Macrocystis pyrifera. Mar. Biol. 56:97-102.

Wright, S. W., Jeffrey, S. W., Mantoura, R. F. C., Llewellyn, C. A., Bjørnland, T., Repeta, D. \& Welschmeyer, N. 1991. Improved HPLC method for the analysis of chlorophylls and carotenoids from marine phytoplankton. Mar. Ecol. Prog. Ser. 77:183-96.

Yamamoto, H. Y., Nakayama, T. O. M. \& Chichester, C. O. 1962. Studies on the light and dark interconversions of leaf xanthophylls. Arch. Biochem. Biophys. 97:168-73.

\section{Supporting Information}

Additional Supporting Information may be found in the online version of this article at the publisher's web site:

Table S1. Pigment concentrations $\left(\mu \mathrm{g} \cdot \mathrm{mg}^{-1}\right.$ $\mathrm{dw}$ ) and DPS of experimental fronds of Macrocystis pyrifera (Day 14) from two different sampling depths $(0.2$ and $4 \mathrm{~m})$, transplanted to $2 \mathrm{~m}$ water depth during January/February (Jan/Feb) and August/September (Aug/Sept) 2012.

Table S2. Characteristics of variable Chl $a$ fluorescence of PSII of experimental fronds of Macrocystis pyrifera (Day 14) from two different sampling depths $(0.2$ and $4 \mathrm{~m})$, transplanted to $2 \mathrm{~m}$ water depth during January/February (Jan/Feb) and August/September (Aug/Sept) 2012.

Table S3. Results of the statistical analysis of response variables $\left(\mathrm{F}_{\mathrm{v}} / \mathrm{F}_{\mathrm{m}}, \mathrm{ETR}_{\max }, \mathrm{E}_{\mathrm{k}}, \alpha\right.$, Chl $a$,
Chl $c$, Fuc, $\beta$-caro, VAZ, DPS, phlorotannins, antioxidants, total lipids, saturated/unsaturated FA ratio) from (a) initial fronds of Macrocystis pyrifera (Day 0), using a two-factor permutational multivariate analysis of variance (PERMANOVA) with the factors sampling time (Ts: January/ February and August/September), sampling depth (Ds: 0.2 and $4 \mathrm{~m}$ ) and their interactions and (b) experimental fronds of $M$. pyrifera (Day 14), using a three-factor PERMANOVA with the factors sampling time (Ts: January/February and August/September), sampling depth (Ds: 0.2 and $4 \mathrm{~m}$ ), incubation depth (Di: $0.2,2$, and $4 \mathrm{~m}$ ) and their interactions.

Table S4. Results from similarity percentage analyses (SIMPER) showing the relative contribution $(\%)$ of single response variables to differences in long- and short-term acclimation.

Table S5. Fatty acid (FA) compositions (mass $\%$ of total fatty acids) of initial fronds of Macrocystis pyrifera, sampled at two different water depths $(0.2$ and $4 \mathrm{~m})$ during January/February (Jan/Feb) and August/September (Aug/Sept) 2012.

Table S6. Results of pair-wise comparisons based on permutation of significant interaction of the factors Sampling time $x$ Sampling depth $x$ Incubation depth on response variables $\left(\mathrm{F}_{\mathrm{v}} / \mathrm{F}_{\mathrm{m}}, \mathrm{ETR}_{\mathrm{max}}\right.$, $\mathrm{E}_{\mathrm{k}}, \alpha$, Chl $a$, Chl $c$, Fuc, $\beta$-caro, VAZ, DPS, phlorotannins, antioxidants, total lipids, saturated/unsaturated FA ratio) from experimental fronds of Macrocystis pyrifera (Day 14). 